\title{
Patterns of utilization and effects of hospital-specific factors on physical, occupational, and speech therapy for critically ill patients with acute respiratory failure in the USA: results of a 5-year sample
}

Clare C. Prohaska ${ }^{1,2^{*}}$ (D) Peter D. Sottile ${ }^{2}$, Amy Nordon-Craft ${ }^{3}$, Matt D. Gallagher ${ }^{4}$, Ellen L. Burnham², Brendan J. Clark², Michael Ho ${ }^{5}$, Tyree H. Kiser ${ }^{6}$, R. William Vandivier², Wenhui Liư, Margaret Schenkman ${ }^{3}$ and Marc Moss ${ }^{2}$

\begin{abstract}
Background: Timely initiation of physical, occupational, and speech therapy in critically ill patients is crucial to reduce morbidity and improve outcomes. Over a 5 -year time interval, we sought to determine the utilization of these rehabilitation therapies in the USA.

Methods: We performed a retrospective cohort study utilizing a large, national administrative database including ICU patients from 591 hospitals. Patients over 18 years of age with acute respiratory failure requiring invasive mechanical ventilation within the first 2 days of hospitalization and for a duration of at least $48 \mathrm{~h}$ were included.

Results: A total of 264,137 patients received invasive mechanical ventilation for a median of 4.0 [2.0-8.0] days. Overall, patients spent a median of 5.0 [3.0-10.0] days in the ICU and 10.0 [7.0-16.0] days in the hospital. During their hospitalization, $66.5 \%, 41.0 \%$, and $33.2 \%(95 \% \mathrm{Cl}=66.3-66.7 \%, 40.8-41.2 \%, 33.0-33.4 \%$, respectively) received physical, occupational, and speech therapy. While on mechanical ventilation, $36.2 \%, 29.7 \%$, and $29.9 \%(95 \% \mathrm{Cl}=36$. 0-36.4\%, 29.5-29.9\%, 29.7-30.1\%) received physical, occupational, and speech therapy. In patients receiving therapy, their first physical therapy session occurred on hospital day 5 [3.0-8.0] and hospital day 6 [4.0-10.0] for occupational and speech therapy. Of all patients, $28.6 \%(95 \% \mathrm{Cl}=28.4-28.8 \%)$ did not receive physical, occupational, or speech therapy during their hospitalization. In a multivariate analysis, patients cared for in the Midwest and at teaching hospitals were more likely to receive physical, occupational, and speech therapy (all $P<0.05$ ). Of patients with identical covariates receiving therapy, there was a median of $61 \%, 187 \%$, and $70 \%$ greater odds of receiving physical, occupational, and speech therapy, respectively, at one randomly selected hospital compared with another (median odds ratio 1.61, 2.87, 1. 70 , respectively).

(Continued on next page)
\end{abstract}

\footnotetext{
* Correspondence: clare.prohaska@ucdenver.edu

${ }^{1}$ Department of Medicine, University of Colorado School of Medicine, Aurora, CO 80045, USA

${ }^{2}$ Division of Pulmonary Sciences and Critical Care Medicine, University of

Colorado School of Medicine, Box C272, 12700 E 19th Ave, Aurora, CO 80045,

USA

Full list of author information is available at the end of the article
}

(c) The Author(s). 2019 Open Access This article is distributed under the terms of the Creative Commons Attribution 4.0 International License (http://creativecommons.org/licenses/by/4.0/), which permits unrestricted use, distribution, and reproduction in any medium, provided you give appropriate credit to the original author(s) and the source, provide a link to the Creative Commons license, and indicate if changes were made. The Creative Commons Public Domain Dedication waiver (http://creativecommons.org/publicdomain/zero/1.0/) applies to the data made available in this article, unless otherwise stated. 
(Continued from previous page)

Conclusions: Physical, occupational, and speech therapy are not routinely delivered to critically ill patients, particularly while on mechanical ventilation in the USA. The utilization of these therapies varies according to insurance coverage, geography, and hospital teaching status, and at a hospital level.

Keywords: Early rehabilitation, Intensive care outcomes, Acute respiratory failure

\section{Background}

Intensive care unit-acquired weakness (ICU-AW) occurs commonly in patients with acute respiratory failure requiring mechanical ventilation [1]. ICU-AW is associated with multiple deleterious outcomes including increased ICU and hospital mortality, prolonged ICU and hospital stay, prolonged duration of mechanical ventilation, and pharyngeal dysfunction that may increase the susceptibility to develop aspiration pneumonia [2-5]. After hospital discharge, ICU survivors are also limited in their physical function, and these decrements in activities of daily living may persist 5 years after hospital discharge [6-10]. As a result, critical care professionals have focused on preventing and treating ICU-AW with the early initiation of physical, occupational, and speech therapy [11-17].

Despite increased awareness about the potential benefits of physical rehabilitation, the frequency, timing, and duration of physical, occupational, and speech therapy for patients with acute respiratory failure requiring mechanical ventilation are relatively unknown. Prior national surveys in the USA and abroad have reported the opinions of healthcare professionals about their perceived practice, yet did not examine actual practice patterns [18-20]. Several point prevalence studies have been published; however, they involved a small number of hospitals and only collected data for a few days [21-26]. Finally, no prior studies examined the effects of insurance status, regional variation, or teaching status of the hospital on physical, occupational, and speech therapy utilization.

Therefore, we sought to determine the national utilization of physical, occupational, and speech therapy for patients with acute respiratory failure requiring mechanical ventilation.

\section{Methods}

\section{Study design}

We performed a retrospective cohort study of the Premier Incorporated Perspective Database, a cohort of over 7 million unique intensive care unit (ICU) admissions nationally from January 2010 through December 2014. The database has been described in detail previously [27-30]. The Colorado Multiple Institutional Review Board approved this study.

\section{Patient population}

Adult patients 18 years or older who were admitted to the ICU with acute respiratory failure were included.
Acute respiratory failure was defined as patients who received invasive mechanical ventilation within the first 2 days of hospitalization, and received at least two consecutive days of mechanical ventilation. Invasive mechanical ventilation was defined by the presence of 39 different possible charges for intubation or mechanical ventilation on each day (see Additional file 1: Table S1). Patients who were transferred from an outside hospital, had repeated admissions in the dataset, or had a hospital stay of less than 4 days were excluded. Physical, occupational, and speech therapy utilization was determined by the presence of specific hospital charge codes (see Additional file 2: Table S2) on each day. Patient characteristics included age, gender, race, and insurance coverage. Categories of insurance coverage were Medicare, Medicaid, private insurance, self-pay, other, or charity. Hospital characteristics included geographic region, hospital size, rural versus urban setting, and academic versus private teaching status. Geographic regions were defined as Northeast, South, Midwest, and West (Additional file 3: Figure S1).

\section{Analysis}

Our primary outcome measures were utilization, time to initiation, and total number of sessions of physical, occupational, and speech therapy during the hospitalization and while on mechanical ventilation.

We fit a Bayesian model with Markov chain Monte Carlo (MCMC) method to the outcomes [31]. To account for hospital-level variation, as well as hospital-level correlation between the three outcomes, a joint mixed effect model with logistic link function was used to evaluate the association between patient insurance coverage (Medicare, Medicaid, private insurance, self-pay, charity, or other with Medicaid as the reference group), geographic region (four regions with Midwest as the reference group), and hospital teaching status (yes/ no with teaching as the reference group) upon the utilization of physical, occupational, and speech therapy. Three outcomes were jointed with correlated hospital random effect. Patient demographic factors such as age, gender, race, and location (urban versus rural) were adjusted in the model. Thirty thousand-iteration simulation with 5000 burning iterations in MCMC procedure was used. We also calculated hospital median odds ratios for each outcome. 
The median odds ratio (MOR) measures variation in prescribing patterns between hospitals, with a value always $\geq 1$. It is the median of all theoretically derived odds ratios between two patients with identical covariate values drawn randomly from any two hospitals; in our case, for the likelihood of therapy prescription at a hospital with higher rates of therapy ordered to a patient at a hospital with a lower level of therapy prescription. In effect, this compares the effect of hospital heterogeneity on therapy prescription to that of the patient-level factors as it uses the same scale as odds ratios obtained for patient-level covariates. A MOR of 1 signifies that there is no difference in therapy prescription between two patients with the same covariates at different hospitals. A higher MOR indicates a higher probability of therapy prescription at one hospital versus another [32].

To evaluate the role of individual physicians in ordering physical, occupational, and speech therapy, we determined the variance in prescribing patterns at the hospital level, assuming that physicians who practice together likely have similar practice patterns. We controlled for this variance as a random effect in our models by using a median odds ratio.

The Python (3.6) scientific ecosystem, which includes the Pandas (23.0), SciPy (1.1), and Statsmodels (0.9) open source software libraries, as well as SAS 9.4, was used for all data and statistical analysis [33-37].

\section{Results}

Over 1.40 million patients required mechanical ventilation during the first 2 days of hospitalization. Of these, 500,328 received at least two consecutive days of mechanical ventilation. Of these patients, 79,223 were transferred from an outside hospital, 23,151 had multiple admissions in the Premier database, 105,128 had a hospital stay less than 4 days, and 51,067 were less than 18 years old. Therefore, a total of 264,137 unique patient admissions from 591 hospitals were included in the final analysis (Fig. 1).

Study population demographics can be found in Table 1. Medicare was the most common insurance coverage at $56.3 \% ; 19.9 \%$ had private insurance, $12.9 \%$ had Medicaid, 5.9\% were self-pay, $4.1 \%$ had other insurance, and $<1.0 \%$ received charity care. A total of $46.4 \%$ of patients were located in the South, $21.0 \%$ located in the Midwest, $17.9 \%$ located in the West, and $14.7 \%$ located in the Northeast. Of the patients included in our study, the median length of intubation was 4.0 days [2.0-8.0], ICU length of stay 5.0 days [3.0-10.0], and hospital length of stay 10.0 days [7.0-16.0] (Table 1). Of the 591 hospitals included in the study, the median number of hospital beds was 234.0 [122.5, 384.0].

\section{Primary analysis}

Overall, 175,611 patients (66.5\%, 95\% CI $=66.3-66.7 \%)$ received physical therapy, 108,312 patients $(41.0 \%, 95 \%$

$1,028,956$ patients requiring $M V$ in first 2 days of hospitalization

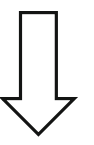

\section{0,328 patients requiring $M V>2$ consecutive days started in the first 2 days of hospitalization}

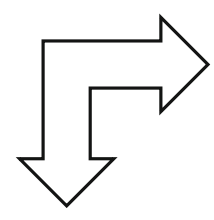

79,223 transferred from outside hospital 23,151 with multiple admissions 105,128 hospital day $<4$ days $57,067<18$ years old

\section{4,137 patients included in data} analysis

Fig. 1 Inclusion flow diagram. Exclusion criteria were not mutually exclusive categories 
Table 1 Demographic information

\begin{tabular}{|c|c|c|c|c|c|c|c|}
\hline Characteristic & $\begin{array}{l}\text { Received PT } \\
(N=175,611)\end{array}$ & $\begin{array}{l}\text { Did not receive } \\
\text { PT }(N=88,526)\end{array}$ & $\begin{array}{l}\text { Received OT } \\
(N=108,312)\end{array}$ & $\begin{array}{l}\text { Did not receive } \\
\text { OT }(N=155,825)\end{array}$ & $\begin{array}{l}\text { Received ST } \\
(N=87,770)\end{array}$ & $\begin{array}{l}\text { Did not receive } \\
\text { ST }(N=176,367)\end{array}$ & $\begin{array}{l}\text { All subjects } \\
(N=264,137)\end{array}$ \\
\hline Mean age (SD) & $63.0(16.3)$ & $61.0(17.2)$ & $62.0(16.8)$ & $62.5(16.6)$ & $62.6(17.2)$ & $62.2(16.4)$ & $62.3(16.6)$ \\
\hline$\%$ Male & 54.3 & 55.3 & 55.1 & 54.3 & 55.7 & 54.1 & 54.6 \\
\hline$\%$ White & 68.8 & 64.9 & 67.9 & 67.3 & 67.1 & 67.7 & 67.5 \\
\hline \multicolumn{8}{|l|}{ Insurance (\%) } \\
\hline Medicare & $100,852(57.4 \%)$ & 47,948 (54.2\%) & 59,535 (55.0\%) & 89,265 (57.3\%) & 49,448 (56.3\%) & 99,352 (56.3\%) & $56.3 \%$ \\
\hline Private & 35,138 (20.0\%) & 17,517 (19.8\%) & 22,682 (20.9\%) & 29,973 (19.2\%) & 16,494 (18.8\%) & 36,161 (20.5\%) & $19.9 \%$ \\
\hline Medicaid & $21,583(12.3 \%)$ & 12,425 (14.0\%) & 14,059 (13.0\%) & 19,949 (12.8\%) & 12,117 (13.8\%) & 21,891 (12.4\%) & $12.8 \%$ \\
\hline Self-pay & 9361 (5.3\%) & $6262(7.1 \%)$ & $6291(5.8 \%)$ & $9332(6.0 \%)$ & $5071(5.8 \%)$ & $10,552(6.0 \%)$ & $5.9 \%$ \\
\hline Other & $7230(4.1 \%)$ & $3542(4.0 \%)$ & 4965 (4.6\%) & 5807 (3.7\%) & 3852 (4.4\%) & $6920(3.9 \%)$ & $4.1 \%$ \\
\hline Charity & $1447(0.8 \%)$ & $832(0.9 \%)$ & $780(0.7 \%)$ & 1499 (1.0\%) & 788 (0.9\%) & $1491(0.8 \%)$ & $0.9 \%$ \\
\hline Median \# of beds & 417 & 390 & 423 & 391 & 423 & 399 & 234 \\
\hline$\%$ Urban & 90.8 & 89.0 & 91.9 & 89.0 & 91.5 & 89.6 & 77.0 \\
\hline \multicolumn{8}{|l|}{ Region (\%) } \\
\hline Midwest & 31,648 (18.0\%) & $14,384(16.2 \%)$ & $25,259(23.3 \%)$ & $20,773(13.3 \%)$ & 15,695 (17.9\%) & 30,337 (17.2\%) & $21.0 \%$ \\
\hline Northeast & 29,744 (16.9\%) & $13,828(15.6 \%)$ & 15,027 (13.9\%) & 28,545 (18.3\%) & $14,550(16.6 \%)$ & $29,022(16.5 \%)$ & $14.7 \%$ \\
\hline South & $85,611(48.8 \%)$ & 45,608 (51.5\%) & 49,306 (45.5\%) & $81,913(52.6 \%)$ & $41,050(46.8 \%)$ & 90,169 (51.1\%) & $46.4 \%$ \\
\hline West & 28,608 (16.3\%) & 14,706 (16.6\%) & 18,720 (17.3\%) & 24,594 (15.8\%) & 16,475 (18.8\%) & 26,839 (15.2\%) & $17.9 \%$ \\
\hline$\%$ Academic & 49.0 & 43.9 & 52.1 & 43.9 & 50.3 & 45.8 & 29.9 \\
\hline $\begin{array}{l}\text { Length of MV (median) } \\
\text { [25-75\% quartile] }\end{array}$ & $4.0[2.0-8.0]$ & $4.0[3.0-7.0]$ & $4.0[2.0-8.0]$ & 3.0 [2.0-6.0] & $5.0[3.0-9.0]$ & 3.0 [2.0-6.0] & $4.0[2.0-8.0]$ \\
\hline $\begin{array}{l}\text { ICU LOS (median) } \\
\text { [25-75\% quartile] }\end{array}$ & $6.0[3.0-10.0]$ & 5.0 [3.0-9.0] & 6.0 [4.0-12.0] & 5.0 [3.0-8.0] & 7.0 [4.0-13.0] & 5.0 [3.0-8.0] & 5.0 [3.0-10.0] \\
\hline $\begin{array}{l}\text { Hospital LOS (median) } \\
{[25-75 \% \text { quartile] }}\end{array}$ & 12.0 [8.0-18.0] & 9.0 [7.0-13.0] & 13.0 [9.0-20.0] & 10.0 [7.0-15.0] & $14.0[9.0-22.0]$ & 10.0 [7.0-14.0] & $10.0[7.0-16.0]$ \\
\hline
\end{tabular}

$\mathrm{CI}=40.8-41.2 \%)$ received occupational therapy, and 87,770 patients $(33.2 \%, 95 \% \mathrm{CI}=33.0-33.4 \%)$ received speech therapy during their hospitalization. Of patients who received rehabilitation during their hospitalization, $36.2 \% \quad(95 \% \quad \mathrm{CI}=36.0-36.4 \%) \quad$ of patients received physical therapy, 29.7\% (95\% CI = 29.5-29.9\%) of patients received occupational therapy, and $29.9 \%(95 \% \mathrm{CI}=29.7-31.1 \%)$ of patients received speech therapy and mechanical ventilation on the same day. Table 2 further details when therapy was initiated and how frequently therapy was delivered while patients were still hospitalized.
Overall, 28.6\% (95\% CI $=28.4-28.8 \%)$ of patients did not receive any type of rehabilitation. The most frequent therapy combination was physical, occupational, and speech therapy, ordered in $21.2 \%$ (95\% CI $=21.0$ $21.4 \%)$ of patients. Physical therapy alone was ordered in $18.6 \%$ (95\% CI $=18.4-18.8 \%)$, and physical and occupational therapy were ordered together in $18.5 \%$ (95\% CI $=18.3-18.7 \%$ ) of patients (Fig. 2).

\section{Multivariable analysis}

The results of a multivariable regression model controlling for payor type, hospital geographic location,

Table 2 Therapy utilization

\begin{tabular}{lll}
\hline Outcomes & Physical therapy & Occupational therapy \\
\hline Received therapy during hospitalization & $175,611(66.5 \%)$ & $108,312(41.0 \%)$ \\
Received therapy and MV on the same day & $63,639(36.2 \%)$ & $32,183(29.7 \%)$ \\
Time to initiation of therapy (days after intubation) & $4.0[2.0-7.0]$ & $5.0[3.0-9.0]$ \\
$\begin{array}{l}25-75 \% \text { quartile] } \\
\text { Length of therapy (days) [25-75\% quartile] }\end{array}$ & $3.0[2.0-6.0]$ & $2.0[1.0-4.0]$ \\
Median odds ratio (SD) & $1.61(0.03)$ & $2.87(0.11)$ \\
\hline
\end{tabular}




\section{\% Therapy Utilization}

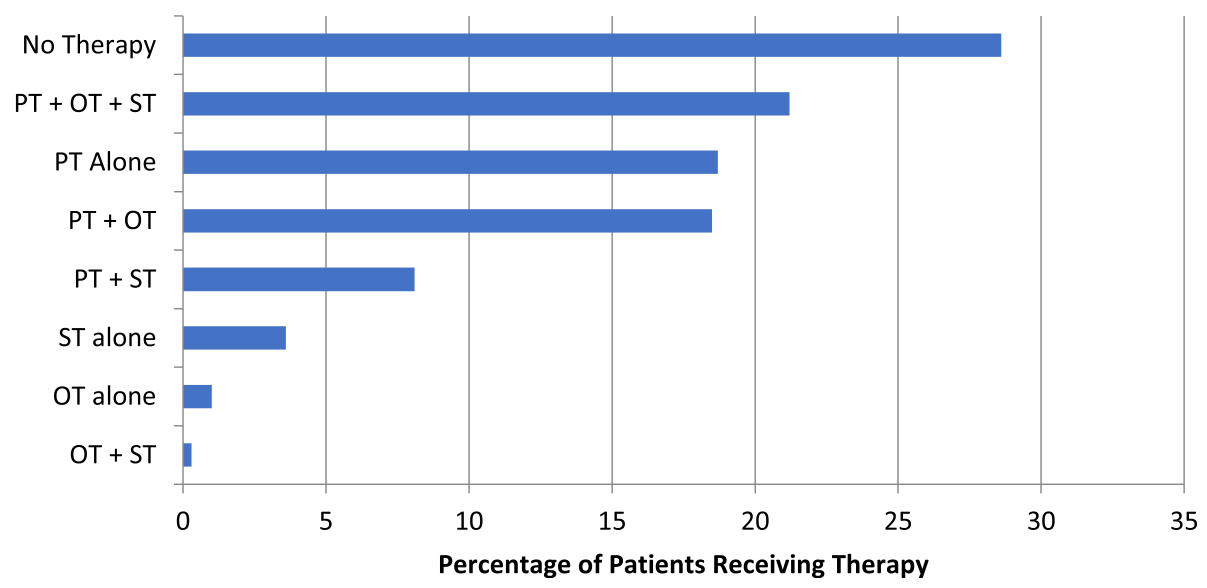

Fig. 2 Therapy ordering patterns. Overall, 75,527 patients (28.6\%) did not receive any therapy. The most common ordering patterns were the combination of physical, occupational, and speech therapy [55,914 patients (21.2\%)] and physical therapy alone [49,297 patients (18.7\%)], followed by physical and occupational therapy [48,910 patients (18.5\%)]. PT physical therapy, OT occupational therapy, ST speech therapy

and hospital teaching status are reported in Table 3. For physical, occupational, and speech therapy, patients were more likely to receive therapy in the Midwest and at teaching hospitals [OR $1.20(95 \%$ CI 1.18-1.22\%), 1.81 (95\% CI 1.47-2.23\%), 1.16 (95\% CI $1.07-1.26 \%)$, respectively]. The median odds ratio was 1.61 for physical therapy, 2.87 for occupational therapy, and 1.70 for speech therapy. This suggests that there was significantly greater variation between hospitals with regard to therapy prescription that cannot be measured by hospital-level characteristics alone. There were 42,049 physicians who admitted the 264,137 patients in our study. Individual physicians were responsible for a median admission of 2 patients [interquartile range 1.0-6.0, $\max 1704$ ].

\section{Discussion}

Critically ill patients with respiratory failure who require invasive mechanical ventilation receive physical, occupational, and speech therapy in a variable manner. Patients were unlikely to receive rehabilitation while on mechanical ventilation. Typically, therapy is initiated several days after hospital admission, and patients receive only a few days of therapy during their hospitalization. Our study found that despite increasing awareness of early mobilization, physical rehabilitation does not happen as early in a hospital stay as

Table 3 Multivariate analysis: association of insurance status, geographic region, and teaching status on therapy orders

\begin{tabular}{|c|c|c|c|c|c|c|c|}
\hline \multirow[t]{2}{*}{ Variable } & & \multicolumn{2}{|c|}{ Physical therapy } & \multicolumn{2}{|c|}{ Occupational therapy } & \multicolumn{2}{|c|}{ Speech therapy } \\
\hline & & $N$ & OR $(95 \% \mathrm{Cl})$ & $\bar{N}$ & OR $(95 \% \mathrm{Cl})$ & $N$ & OR $(95 \% \mathrm{Cl})$ \\
\hline \multirow[t]{6}{*}{ Payor } & Medicaid & 21,583 & - & 14,059 & - & 12,117 & - \\
\hline & Medicare & 100,852 & $1.02(0.99-1.05)$ & 59,535 & $0.96^{*}(0.94-0.97)$ & 49,448 & $0.87^{*}(0.86-0.89)$ \\
\hline & Private & 35,138 & $1.04^{*}(1.01-1.07)$ & 22,682 & $1.01(0.98-1.03)$ & 16,494 & $0.80^{*}(0.79-0.81)$ \\
\hline & Self-pay & 9361 & $0.88^{*}(0.86-0.89)$ & 6291 & $0.89 *(0.85-0.93)$ & 5071 & $0.88^{*}(0.86-0.89)$ \\
\hline & Other & 7230 & $1.13^{*}(1.12-1.15)$ & 4965 & $1.20^{*}(1.14-1.25)$ & 3852 & $0.98(0.93-1.03)$ \\
\hline & Charity & 1447 & $0.94(0.86-1.03)$ & 780 & $0.90^{*}(0.84-0.95)$ & 788 & $0.88^{*}(0.80-0.97)$ \\
\hline \multirow[t]{4}{*}{ Region } & Midwest & 31,648 & - & 25,259 & - & 15,695 & - \\
\hline & West & 29,744 & $0.85^{*}(0.74-0.98)$ & 15,027 & $0.57^{*}(0.43-0.77)$ & 14,550 & $1.09(0.93-1.28)$ \\
\hline & Northeast & 85,611 & $0.76^{*}(0.66-0.88)$ & 49,306 & $0.26^{*}(0.19-0.36)$ & 41,050 & $0.79^{*}(0.67-0.94)$ \\
\hline & South & 28,608 & $0.79^{*}(0.70-0.88)$ & 18,720 & $0.32^{*}(0.25-0.40)$ & 16,475 & $0.79^{*}(0.70-0.90)$ \\
\hline \multirow[t]{2}{*}{ Teaching status } & Private & 89,597 & - & 51,832 & - & 43,661 & - \\
\hline & Academic & 86,014 & $1.20^{*}(1.8-1.22)$ & 56,480 & $1.81^{*}(1.47-2.23)$ & 44,109 & $1.16^{*}(1.07-1.26)$ \\
\hline
\end{tabular}


may be possible. Furthermore, we found that there are variations with how rehabilitation is delivered related to insurance status, geographic region, and hospital teaching status.

With the increasing awareness of ICU-AW, there has been increased interest in the early utilization of these therapies. Previous studies were either surveys that measured perceptions of delivery of care, only examined limited numbers of hospitals, or were point prevalence studies a few days throughout the year. These previous study designs might not accurately reflect utilization trends in the USA. For example, two previous studies sent surveys to ICU providers, who estimated that between 39 and $47 \%$ patients on mechanical ventilation underwent early mobilization $[18,19]$. However, point prevalence studies suggest that this is a significant overestimation. In a recent study by Jolley et al. of 42 ICUs over 2 days, only $16 \%$ of mechanically ventilated patients achieved out of bed mobility [22]. Other international surveys from countries such as France, Germany, and the UK estimate early mobility at $40 \%, 59 \%$, and $52 \%$, respectively [20], while point prevalence studies from Germany, Australia, and New Zealand reported that 0-3\% of patients receive physical therapy while on mechanical ventilation [23-26]. Our data showed that $24.1 \%$ of patients received physical therapy and mechanical ventilation codes on the same day, an intermediate value between these two estimates. It is possible that with increased awareness of ICU-AW, providers are ordering these therapies more frequently while patients still require mechanical ventilation, or very soon after extubation.

Bakhru et al. surveyed ICUs in four different countries. There was wide variation amongst dedicated physical therapists (34\% in the USA versus $92 \%$ in the UK), as well as a nurse to patient ratios (typically $1: 1$ in the UK and up to 1:4 in France). They found that early mobilization was significantly associated with a lower nurse to patient staffing ratio, presence of dedicated physical therapists (therapist who is primarily assigned to patients in the ICU), and multidisciplinary rounds (rounds consisting of physicians, nurses, and other healthcare workers such as social workers, physical or respiratory therapists, or pharmacists). Early mobility was not associated with academic affiliation [20].

Despite a robust investigation of early physical therapy, less understanding of the role of occupational and speech therapy exists. One single-center study regarding the independent use of occupational therapy demonstrated a utilization rate of $30 \%$ in ICU patients [38]. We found that during an entire hospital stay, this rate was only $41.0 \%$ and reduced to only $12.2 \%$ of patients on mechanical ventilation. Similarly, we found that speech therapy was ordered in $33.2 \%$ of all patients. If not recognized early, patients may be vulnerable to post-extubation dysphagia, which has been shown to lead to poor patient outcomes and longer hospital stays in certain patient populations $[39,40]$. In an observational study, the prevalence of dysphagia was $84 \%$ in patients recovering from critical illness; however, only $25 \%$ of these patients received a speech therapy consultation [41]. Speech therapy may be an underutilized resource, and further studies regarding long-term follow-up of early interventions are warranted.

To our knowledge, no previous studies have shown differences in the utilization of physical, occupational, or speech therapy based on insurance status, geographic variation, or hospital teaching status. There was significant variation between insurance coverage and therapy implementation; if the utilization of therapy leads to improved outcomes and is cost-effective, this may lead to broader therapy utilization in the future. Since the conduct of this study, the USA enacted the Affordable Care Act. Whether this policy change had any effect on ordering patterns of physical rehabilitation is unknown, and this could be explored in future studies. Given the observational nature of our study, it was impossible to factor in clinician decision making. It is therefore unknown if patient insurance status had any effect on whether the clinician decided to order rehabilitation services.

Geographic differences may reflect local or regional hospital culture related to different training of providers, highlighted by median odds ratios calculated for each therapy type. Although there has been no published research reporting how geography plays a role in physical rehabilitation in the ICU, there have been previous studies that show patients who must travel longer distances have decreased rates of healthcare utilization $[42,43]$. It could be extrapolated that patients in the Midwest are generally located in more rural settings, and thus, providers in this region are more cognizant of limited exposure to healthcare and thus order physical rehabilitation more frequently than other regions. Studies detailing early mobility in the USA are typically performed at major cities or academic centers [12-17], so it is unclear how their results are generalizable to more rural settings or other countries. Furthermore, we found that teaching hospitals were more likely than non-teaching hospitals to provide therapy, possibly indicating that during training, providers are increasingly utilizing physical, occupational, and speech therapy. Unfortunately, there are no studies currently available that report other countries' physical rehabilitation patterns with respect to geography or insurance coverage. It remains unclear if countries with nationalized healthcare have any difference in physical rehabilitation ordering patterns [23-26].

There are several important limitations to this observational study. First, our data was collected between 2010 and 2014. It is possible that the utilization of these therapies has changed in recent years since awareness of early mobility has increased. Second, we used therapy codes as a marker for therapy intervention. Some patients received 
therapy codes that might have only been evaluated by a therapist and not actually received any therapy. Therefore, our findings may overestimate the true delivery of rehabilitative interventions. Third, it is possible that early consultation is not always warranted, for example, speech therapy consultation while a patient remains on mechanical ventilation. Currently, there are no ways to identify patients who would receive additional benefit from early physical, occupational, and speech therapy, and further research is indicated. Fourth, given the nature of this data set, it is unclear if certain clinicians order physical rehabilitation more frequently than others. It is possible that certain providers are more consistent about ordering physical rehabilitation early into a hospital stay compared to other physicians, which may also vary with geography or hospital teaching status. There are likely other hospital factors that influence physical rehabilitation ordering patterns, such as patient to provider ratio or number of patient comorbidities. Fifth, the data utilized in this study was generated only from hospitals in the USA, and results in other countries, particularly those with nationalized healthcare systems, may be different. Finally, this is an observational study and thus causal associations cannot be determined. Additional studies are necessary to see how prescribing patterns are affecting long-term patient outcomes, how increased multidisciplinary care can be achieved in the ICU, and how these patterns are changing over time.

\section{Conclusions}

Critically ill patients receive physical, occupational, and speech therapy in a variable manner during their hospitalization, and only a minority while on mechanical ventilation. On average, rehabilitation is initiated several days after admission, and only few sessions are completed prior to discharge. Patients with private insurance, located in certain areas of the country or cared for at teaching hospitals are most likely to receive early rehabilitation. Further studies are needed to determine how these differences affect long-term patient morbidity and recovery.

\section{Additional files}

Additional file 1: Table S1. Mechanical ventilation charge codes. (DOCX $15 \mathrm{~kb})$

Additional file 2: Table S2. Physical, occupational, and speech therapy utilization codes. (DOCX $26 \mathrm{~kb}$ )

Additional file 3: Figure S1. Geographic regions. (DOCX 65 kb)

\section{Abbreviations}

ICU: Intensive care unit; ICU-AW: Intensive care unit-associated weakness; MCMC method: Markov chan Monte Carlo method; MOR: Median odds ratio; OT: Occupational therapy; PT: Physical therapy; ST: Speech therapy

\section{Acknowledgements}

The authors would like to thank Mr. Richard Allen for his initial assistance with analysis of the dataset.

\section{Funding}

Funding was provided by K24 HL-069223, an institutional grant from the $\mathrm{NIH-NHLBI}$ that is current.

\section{Availability of data and materials}

The data that support the findings of this study are provided by the Premier Incorporated Perspective Database, a private database to which the authors subscribe, and so, data are not publicly available. Data from January 2010 through December 2014 was included in the analysis.

\section{Authors' contributions}

CCP is the guarantor of the content of this manuscript. PDS and WL had full access to all the data in the study. ANC, MDG, ELB, BJC, MH, THK, RWV, MS, and $\mathrm{MM}$ contributed to the data analysis, interpretation, and writing of the manuscript. All authors read and approved the final manuscript.

\section{Ethics approval}

Not applicable

\section{Consent for publication \\ Not applicable}

\section{Competing interests}

The authors declare that they have no competing interests.

\section{Publisher's Note}

Springer Nature remains neutral with regard to jurisdictional claims in published maps and institutional affiliations.

\section{Author details}

'Department of Medicine, University of Colorado School of Medicine, Aurora, CO 80045, USA. ${ }^{2}$ Division of Pulmonary Sciences and Critical Care Medicine, University of Colorado School of Medicine, Box C272, 12700 E 19th Ave, Aurora, CO 80045, USA. ${ }^{3}$ Department of Physical Therapy, University of Colorado Hospital, Aurora, CO 80045, USA. ${ }^{4}$ University of Colorado Hospital, Aurora, CO 80045, USA. ${ }^{5}$ Division of Cardiology, University of Colorado School of Medicine, Aurora, CO 80045, USA. ${ }^{6}$ Department of Clinical Pharmacy, University of Colorado School of Pharmacy and Pharmaceutical Sciences, Aurora, CO 80045, USA. VA Eastern Colorado Health Care System, Aurora, CO 80045, USA.

Received: 24 January 2019 Accepted: 5 May 2019

Published online: 16 May 2019

\section{References}

1. Needham DM, Davidson J, Cohen $\mathrm{H}$, et al. Improving long-term outcomes after discharge from intensive care unit: report from a stakeholders' conference. Crit Care Med. 2012;40:502-9.

2. De Jonghe B, Sharshar T, Lefaucheur JP, et al. Paresis acquired in the intensive care unit: a prospective multicenter study. JAMA. 2002;288:285967.

3. Sharshar T, Bastuji-Garin S, Stevens RD, et al. Presence and severity of intensive care unit-acquired paresis at time of awakening are associated with increased intensive care unit and hospital mortality. Crit Care Med. 2009;37:3047-53.

4. De Jonghe B, Bastuji-Garin S, Durand MC, et al. Respiratory weakness is associated with limb weakness and delayed weaning in critical illness. Crit Care Med. 2007;35:2007-14.

5. Mirzakhani H, Williams JN, Mello J, et al. Muscle weakness predicts paryngeal dysfunction and symptomatic aspiration in long-term ventilated patients. Anesthesia. 2013;19:389-97.

6. Herridge MS, Cheung AM, Tansey CM, et al. One-year outcomes in survivors of the acute respiratory distress syndrome. N Engl J Med. 2003;348:683-93.

7. Herridge MS, Tansey CM, Matté A, et al. Functional disability 5 years after acute respiratory distress syndrome. N Engl J Med. 2011;364:1293-304. 
8. Fletcher SN, Kennedy DD, Ghosh IR, et al. Persistent neuromuscular and neurophysiologic abnormalities in long-term survivors of prolonged critical illness. Crit Care Med. 2003;31:1012-6.

9. Hermans $G$, Van den Berghe $G$. Clinical review: intensive care unit acquired weakness. Crit Care. 2015;19:274.

10. Desai SV, Law TJ, Needham DM. Long-term complications of critical care Crit Care Med. 2011;39:371-9.

11. Morris PE, Griffin L, Berry M, et al. Receiving early mobility during an ICU admission is a predictor of improved outcomes in acute respiratory failure. Am J Med Sci. 2011;341:373-7.

12. Schweickert WD, Pohlman MC, Pohlman AS, et al. Early physical and occupational therapy in mechanically ventilated, critically ill patients: a randomized controlled trial. Lancet. 2009;373:1874-82.

13. Morris PE, Goad A, Thompson C, et al. Early intensive care unit mobility therapy in the treatment of acute respiratory failure. Crit Care Med. 2008;36: 2238-43.

14. Denehy $L$, Skinner EH, Edbrooke $L$, et al. Exercise rehabilitation for patients with critical illness: a randomized controlled trial with 12 months of follow up. Crit Care. 2013;17:R156.

15. Moss M, Nordon-Craft A, Malone D, et al. A randomized trial of an intensive physical therapy program for acute respiratory failure patients. Am J Respir Crit Care Med. 2016;193:1101-10.

16. Corcoran JR, Herbsman JM, Bushnik T, et al. Early rehabilitation in the medical and surgical intensive care units for patients with and without mechanical ventilation: an interprofessional performance improvement project. PM R. 2017:9:113-9.

17. Schefold JC, Berger D, Zurcher P, et al. Dysphagia in mechanically ventilated ICU patients (DYnAMICS): a prospective observational trial. Crit Care Med. 2017;45:2061-9.

18. Miller MA, Govindan S, Watson SR, et al. ABCDE, but in that order? A crosssectional survey of Michigan ICU sedation, delirium and early mobility practices. Ann Am Thorac Soc. 2015;12:1066-71.

19. Jolley SE, Dale CR, Hough CL. Hospital-level factors associated with report of physical activity in patients on mechanical ventilation across Washington State. Ann Am Thorac Soc. 2015;12:209-15.

20. Malone D, Ridgeway K, Nordon-Craft A, et al. Physical therapist practice in the intensive care unit: results of a national survey. Phys Ther. 2015;95:1335-44.

21. Bakhru RN, McWilliams DJ, Wiebe DJ, et al. Intensive care unit structure variation and implications for early mobilization practices. Ann Am Thorac Soc. 2016:13:1527-37.

22. Jolley SE, Moss M, Needham DM, et al. Point prevalence study of mobilization practices for acute respiratory failure patients in the United States. Crit Care Med. 2017;45:205-15.

23. Berney SC, Harrold M, Webb SA, et al. Intensive care unit mobility practices in Australia and New Zealand: a point prevalence study. Crit Care Resusc. 2013;15:260-5.

24. The TEAM Study Investigators. Early mobilization and recovery in mechanically ventilated patients in the ICU: a bi-national, multi-centre, prospective cohort study. Crit Care. 2015;19:81.

25. Nydahl P, Ruhl AP, Bartoszek G, et al. Early mobilization of mechanically ventilated patients: a 1-day point-prevalence study in Germany. Crit Care Med. 2014;42:1178-86.

26. Lee $H, K_{0}$ YJ, Suh GY, et al. Safety profile and feasibility of early physical therapy and mobility for critically ill patients in the medical intensive care unit: beginning experiences in Korea. J Crit Care. 2015;30:673-7.

27. Lindenauer PK, Pekow PS, Lahti MC, et al. Association of corticosteroid dose and route of administration with risk of treatment failure in acute exacerbation of chronic obstructive pulmonary disease. JAMA. 2010;303: 2359-67.

28. Mercaldi CJ, Reynoldss MW, Turpin RS. Methods to identify and compare parenteral nutrition administered from hospital-compounded and premixed multichamber bags in a retrospective hospital claims database. JPEN J Parenter Enter Nutr. 2012;36:330-6.

29. Rothberg MB, Pekow PS, Lahti M, et al. Antibiotic therapy and treatment failure in patients hospitalized for acute exacerbation of chronic obstructive pulmonary disease. JAMA. 2010;303:2035-42

30. Schneeweiss S, Seeger JD, Landon J, et al. Aprotinin during coronary-artery bypass grafting and risk of death. N Engl J Med. 2008;358:771-83.

31. Browne WJ, Charlton C, Rabash J. MCMC estimation in MLwiN version 2.32. United Kingdom: University of Bristol; 2015. p. 1-18. Available at http:// www.bris.ac.uk/cmm/media/software/mlwin/downloads/manuals/2-32/ mcmc-web.pdf

32. Vigen $\mathrm{R}$, Maddox TM, O'Donnell $\mathrm{Cl}$, et al. Hospital variation in premature clopidogrel discontinuation after drug-eluting stent placements in the Veterans Affairs (VA) healthcare system. J Am Heart Assoc. 2016;5:e001376.

33. Oliphant TE. Python for scientific computing. Comput. Sci. Eng. 2007;9:10-20.

34. Millman KJ. Aiazis: Python for scientists and engineers. Comput. Sci. Eng 2011;13:9-12.

35. Jones E, Oliphant E, Peterson P et al: SciPy: open source scientific tools for python. Available at http://www.scipy.org/. Accessed 14 Aug 2018.

36. McKinney W. Data structures for statistical computing in python. Proceedings of the $9^{\text {th }}$ Python in Science Conference; 2010. p. 51-6.

37. Seabold S, Perktold J. Statsmodels: econometric and statistical modeling with python. Proceedings of the $9^{\text {th }}$ Python in Science Conference; 2010. p. 57-61.

38. Dinglas VD, Colantuoni $\mathrm{E}$, Ciesla N, et al. Occupational therapy for patients with acute lung injury: factors associated with time to first intervention in the intensive care unit. Am J of Occupational Ther. 2013;67:355-62.

39. Macht M, Wimbish T, Clark BJ, et al. Postextubation dysphagia is persistent and associated with poor outcomes in survivors of critical illness. Crit Care. 2011;15:R231.

40. Macht M, White D, Moss M. Swallowing dysfunction after critical illness. Chest. 2014:146:1681-9.

41. Skoretz SA, Flowers HL, Martino R. The incidence of dysphagia following endotracheal intubation: a systematic review. Chest. 2010:137:665-73.

42. Bell N, Kidanie T, Cai B, et al. Geographic variation in outpatient health care service utilization after spinal cord injury. Arch Phys Med Rehabil. 2017:98:341-6.

43. LaVela SL, Smith B, Weaver FM, et al. Geographical proximity and health care utilization in veterans with SCI\&D in the USA. Soc Sci Med. 2004:59: 2387-99.

Ready to submit your research? Choose BMC and benefit from:

- fast, convenient online submission

- thorough peer review by experienced researchers in your field

- rapid publication on acceptance

- support for research data, including large and complex data types

- gold Open Access which fosters wider collaboration and increased citations

- maximum visibility for your research: over $100 \mathrm{M}$ website views per year

At $\mathrm{BMC}$, research is always in progress.

Learn more biomedcentral.com/submissions 